\title{
Evaluating Membership in a Resource-Sharing Program: The Center for Research Libraries
}

\section{John Rutledge and Luke Swindler}

This article examines arguments in favor of membership in the Center for Research Libraries in light of its changing collections and services, the changing environment of cooperative collection development, and the changing needs and fiscal situations of research libraries. The classic arguments for participation are discussed from both theoretical and practical perspectives, using the experience of the University of North Carolina at Chapel Hill and other $C R L$ members as cases in point. Four evaluation methodologies encompassing the major quantifiable benefits of membership are also assessed.

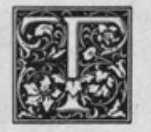

he Center for Research Libraries (CRL) is often cited as one of the premier examples of library cooperation. Yet, little has been published on the center and much of that has been reportage or promotional in nature. ${ }^{1}$ Is the center so good that there simply is no controversy? Recent declines in membership indicate the contrary. In addition, consultants who surveyed collection development librarians at CRL member institutions (hereafter referred to as the MGF report) found that only half considered membership a good investment. $^{2}$

Rapid changes in the financial and technological environment of libraries have forced many institutions to reevaluate their collection development programs and reexamine their commitments to cooperative options, including reviewing CRL membership. The benefits of full membership are examined here, based on the experiences of the University of North Carolina at Chapel Hill (UNC-CH) and other member libraries. ${ }^{3,4}$

Periodic examination of a large membership charge is a principle of sound management. Indeed, the center itself encourages members to assess benefits received. That so few libraries have carefully evaluated their membership reflects, in part, the sheer complexity of doing so. We hope to contribute to this important task by providing a critical analysis of the arguments for belonging to the center from both theoretical and practical perspectives and offering specific methodologies for evaluating quantifiable membership benefits.

\section{EVOLUTION}

CRL traces its origins to the creation of the Midwest Inter-Library Center in 1949, which merged the older concepts of central storage and cooperative acquisitions. ${ }^{5}$ Originally its mission included the provi-

John Rutledge is West European Bibliographer and Luke Swindler is Social Sciences Bibliographer at the University of North Carolina, Chapel Hill, North Carolina 27599.

The authors wish to thank Patricia Dominguez, James Govan, Joe Hewitt, Jack Shipman, and Donald Simpson for critiquing earlier versions of this article. 
sion of centralized cataloging and the acquisition of materials to be housed in local collections, but these functions were never developed. As a consequence, the center has been primarily a source of collections rather than services.

Starting with ten founding institutions, CRL reached a total of twenty-one members (all university libraries except for John Crerar) in 1963-64, which was its last year as a regional consortium. Realizing that a larger membership base was essential to support expanded programs, the center eliminated geographical restrictions in 1961, and four years later adopted its present name in order to avoid any hint of regionalism. Recognizing that smaller and more specialized institutions could use its holdings, CRL created an associate membership category several years later. Associates are viewed primarily as users; unlike full members (designated as "voting members"), they have limited governance rights and much lower fees. A third category of user members has just been created for small academic, corporate, or governmental libraries that simply want access to CRL's collections.

Membership grew modestly during the affluent $1960 \mathrm{~s}$, reaching thirty-three by 1968 . But by 1980 , more than 180 institutions belonged, coinciding with the proliferation of consortia and library resourcesharing programs in response to the hard economic times of the seventies. ${ }^{6}$ Membership growth so closely paralleling general trends throughout the 1960 s and 1970 s indicates that the overall economic and political climate for cooperation, rather than any changes in the center's programs or services, was the most significant factor in this growth.

"The center now has 97 full and 42
other members, representing cumu-
lative losses from 1982 of 26 percent
and 37 percent, respectively."

While cooperative programs continue to flourish generally, membership in CRL began to stagnate in the 1980 s, peaking in 1982 at 131 full members and 67 associates . Since then, the number of both full and associate members has decreased each year. The center now has 97 full and 42 other members, representing cumulative losses from 1982 of 26 percent and 37 percent, respectively. Discussions of membership now occur regularly at the center's board of directors meetings and figure prominently in internal reports.

In the 1960 s and 1970 s the dynamics of membership growth related mainly to exogenous factors, whereas the recent decline in members seems related primarily to controversies over the cost and nature of programs and services. Concerns about the level of fees and the equitable determination of membership charges have marked CRL's history. Within a few years of its founding the center's board discussed one university president's disgruntlement with its "growing tendency to function on a more grandiose basis which would require larger and larger assessments on individual members. ${ }^{17}$ More recently, the MGF report found that each of ten former CRL members surveyed indicated high cost as the primary factor in the decision to withdraw.

The nature of the center's programs has also aroused controversy, particularly whether it would remain solely a collection of specialized research materials or also become a major document delivery source. Responding to the problems faced by libraries in meeting users' serials needs, CRL initiated the Journal Access Service (JAS) in 1975 to supply photocopies of needed articles from the British Library Document Supply Centre. Although expensive, JAS increased overall member usage significantly-accounting for half of all requests filled by the early 1980 s-and attracted many new members. ${ }^{9}$ The reassertion of the center's traditional emphasis on collection building led it to levy surcharges on JAS transactions in 1982 and abandon the service in 1986. Without this program, overall use of the center decreased dramatically, refueling the debate regarding the cost and benefits of membership. 


\section{ARGUMENTS FOR MEMBERSHIP}

The arguments for membership need to be reexamined for validity, logic, appeal, and applicability. Membership decisions should take into account all pertinent arguments and put them in proper context. Some appeal more than others; some appeal more at certain times. Not all benefits apply to every institution.

\section{The Obligation to Cooperate}

Research libraries have a duty to provide highly specialized and low-use materials. CRL represents one means of achieving this goal. As its director of collection development recently wrote, the center "collects and provides access to, through interlibrary loans, material that, while essential for research, is apt to be so infrequently used at any one institution that it can be shared by the major research libraries." 10 The importance of this function is succinctly captured by Maurice Glicksman when he calls CRL a "gift to all scholars in the world, and not just those resident in our institutions or community."

Cooperation among libraries is an ideal with many adherents. A recent survey of Association of Research Libraries (ARL) institutions by Joe Hewitt and John Shipman found that 67 percent participated in some form of cooperative collection development. Moreover, even those respondents reporting no cooperative activities "seemed as favorably disposed to the idea of cooperative collection development as those in libraries actively engaged in programs. ${ }^{12}$ It is difficult to speak against cooperation.

The center, however, is not universally perceived as an example of library cooperation. The same study also found that only 13 percent of ARL libraries' reported CRL membership as a "cooperative venture," even though 76 percent were members. ${ }^{13}$ If the center is not a cooperative endeavor, then what is it?

The MGF report found a basic division among respondents over whether the center is "an extension of a library's own collection or a major source of interlibrary loan." Respondents who see CRL as an extension have "a strong philosophical commitment to the CRL," while the second group is "more disposed to evaluating the value of membership in terms of cost per item borrowed." Full members tend to hold the former opinion and associate members the latter; however, even within a given library differences of opinion exist. ${ }^{14}$

Among those members who regard CRL primarily as a cooperative collection development program and an extension of local holdings, other cooperative options have arisen and bid for attention. Within this context, perhaps another reason few ARL libraries cite the center as an example of cooperation is because they view it as minor compared with other programs. Growth in local, regional, and national resource-sharing programs may have diluted the appeal and importance of CRL. ${ }^{15}$

The University of North Carolina at Chapel Hill, for example, has been involved in wide-ranging cooperative collection development programs with the nearby libraries at Duke University and North Carolina State University for over a half-century. These programs, which now fall under the Triangle Research Libraries Network (TRLN), have concentrated on foreign area studies, major microform sets, government publications, newspapers, and specialized serials-precisely the areas that the center has targeted as its selling points. These local resourcesharing agreements also provide bibliographic and physical access generally superior to that supplied by CRL, by including swifter interlibrary loan plus telefacsimile transmission and a union online catalog. ${ }^{16}$

Although UNC-CH considers its membership in the center important and useful, it is marginal in comparison to local resource-sharing arrangements. TRLN cooperative partners filled over ten times as many interlibrary loan requests in 1986-87 as CRL. Indeed, TRLN's success in coordinating the development of research collections locally is one reason why TRLN libraries do not belong to the Research Libraries Group (RLG) and other cooperative ventures. It also partially explains 
why North Carolina State has only recently joined the center and Duke still is not a member of CRL.

The development of other national resource-sharing programs has increased competition for the cooperative dollar. Recent studies of CRL membership by RLG participants-in particular, a thorough study by the University of Michiganhave stressed the need to monitor the center's utility in comparison with what research materials the RLG members can supply. ${ }^{17}$ Already some RLG institutions, such as Johns Hopkins, cite increased access to other research collections over the last several years as a reason for withdrawing from CRL. ${ }^{18}$ Others that have withdrawn also cite the high cost of membership in RLG as an economic factor lim-

"'Although the Center's collections are large and extensive, it is only in a very, very few areas that they are sufficiently comprehensive to be relied upon by North American research libraries to the point where libraries can discontinue collection development in specific fields of publication.'

iting participation in the center. ${ }^{19}$

Even libraries not in major local or national consortia report that arrangements with other institutions not only provide them with needed research materials but also do so more expeditiously than CRL. As a result, some found their use of the center was low, and they decided to withdraw. ${ }^{20}$ The widespread participation of libraries in the North American Collections Inventory Project (NCIP) may give CRL added competition. ${ }^{21}$ In particular, the NCIP conspectus, through its identification of primary collection commitments, may encourage the development of alternatives to the center's collections. On this score, Joseph A. Rosenthal's assessment of CRL holdings is most pertinent: "Although the Center's collections are large and extensive, it is only in a very, very few areas that they are sufficiently comprehensive to be relied upon by North American research libraries to the point where libraries can discontinue collection development in specific fields of publication."'22

These developments indicate a consensus that libraries are obliged to cooperate to assure the availability of low-use research materials. The cooperative options, however, are now greater than before, and some libraries are evidently concluding, rightly or wrongly, that CRL is not the best way to achieve the desired ends. Whether or not the cooperative argument in favor of membership in the center is valid, therefore, depends on what other cooperative arrangements a library has. It further depends on how well CRL functions as a library's library and whether its collections and services are unique.

\section{The Library's Library}

The center is often described as a "library's library," providing access to specialized and low-use research materials that cannot or should not be acquired locally. Indeed, CRL defines itself officially as "a collection that complements and supplements the collections of major research libraries of North America." ${ }^{\prime 23}$ This argument has been one of the most attractive to librarians, especially library directors. ${ }^{24}$ The center is concerned with how well it meets this objective and its recent annual reports repeatedly mention tightening up collection development policies and abandoning collecting areas that overlap with the efforts of members or are of questionable value.

To make effective use of the center as a library's library, a member must determine whether its holdings do in fact complement and supplement local collections. The fact that CRL's holdings fall into distinct categories, such as foreign dissertations and state documents, facilitates such an appraisal. Not all collections are cataloged, however. The lack of adequate bibliographic access to specific titles in its collections is cited as being "the greatest barrier to their use. ${ }^{\prime 25}$ The recent appearance of a microfiche holdings catalog and the center's decision to catalog its titles 
through national bibliographic networks have gone a long way toward solving this problem.

Still, the more fundamental issue remains of whether any distant library can be a "library's library" to so diverse a group of institutions. Full members range in size from less than a million to more than eleven million volumes. A look at figures on institutional size shows that full membership is skewed toward libraries holding fewer than two million volumes. Approximately 70 percent fall into this category. A significant number of larger institutions-including the largest research libraries in the country-form the second major category of members. These differences in size, in turn, result in differences between larger and smaller members over what are appropriate acquisitions. ${ }^{26}$ Tension within such a diverse constituency is inherent, because needs are different. Will a general university such as Harvard require the same large microform sets as a technological institution such as MIT? ${ }^{27}$

CRL membership is evidently not for everyone. A substantial number of research libraries are not members. Indeed, of the 117 ARL libraries only 73-or roughly twothirds-belong. In addition, the trend is for middle-size or small ARL libraries to join, further diversifying the membership. ${ }^{28}$

Moreover, even major research libraries are not always in agreement on which programs are appropriate to a library's library, as evidenced by the lively debate on expanded access to periodical literature. ${ }^{29}$ One therefore must ask the more fundamental question of whether this diverse membership can be squared with a rational collection development policy? If not, whose interests will be favored? At a self-serving level, a library might ask if enough institutions similar to it are in CRL so that at least some decisions will serve its interests.

After intense debate in the early 1980 s members agreed that CRL's focus should be its collections. The center has also made substantial progress in rationalizing its acquisitions policies and making individual items bibliographically accessible. The re- emphasis on its traditional specialized holdings covering a wide subject range has made CRL a more effective library's library for major universities, but it has also made membership less attractive to small or more specialized institutions. For the latter group-particularly those not supporting high volumes of research in the humanities and foreign area studies-the library's library argument carries little weight because the center's collections generally are not relevant to their users' needs. ${ }^{30}$ For major, general research libraries, on the other hand, the effectiveness of the library's library argument means that CRL will have to be supported by a limited full membership base and high annual fees. ${ }^{31}$

\section{Unique Collections and Services}

Arguments in favor of membership in the center would be weakened if its collections and services were available through other means. Therefore, the question of uniqueness is crucial. As a matter of policy, CRL increasingly emphasizes uniqueness or infrequency of holdings. The center's serials review project, in which journals were canceled if held by more than twenty research libraries in North America, is a prime example. Similarly, the center does not purchase microform sets held by and available from more than five members.

Yet the MGF report's survey of former members discovered that only a fifth of them found CRL's programs difficult to replace. ${ }^{32}$ The crux of the matter is whether the center provides anything that simply cannot be obtained elsewhere. Generally this does not seem to be the case. A recent study of CRL's serials holdings found that only 21 percent were unique. ${ }^{33}$ In terms of items actually needed, the MGF report noted that "one academic library checked all of its previous year's CRL requests in the OCLC database and found nearly 95 percent of items" - then withdrew. ${ }^{34}$ In another case, one small ARL library found that all items requested from CRL in 1986 were available elsewhere, which prompted its director to raise the issue of reevaluating membership. 
UNC-CH's study found that only occasionally were materials obtained from CRL that could not be had in any other way. ${ }^{35}$ The same was true for even the smallest members with limited collections. Wichita State University, which withdrew because of low use, stated that "[v]ery little, save an occasional foreign dissertation, was not available elsewhere. ${ }^{136}$ In addition, the director of a smaller ARL library stated that even four years after dropping out of CRL not a single item had been acquired as a result of the change. When viewed solely in terms of bibliographic availability, the uniqueness argument generally does not hold. Nevertheless, the UNC-CH study demonstrated that for materials not held elsewhere, most users indicated their research would have been adversely affected without items from CRL. ${ }^{37}$ The types of materials in this category are foreign dissertations, state documents, periodicals, large microform sets, and on-demand purchases.

Mere bibliographic availability - the fact that one can locate an item in a library other than the center-can be misleading. Some libraries will not lend certain types of materials, while others that do often levy fees. Even if the material can be obtained on interlibrary loan, many libraries will allow only a short loan period or send only a limited quantity of material at any one time. Such restrictions can cause problems for researchers, particularly in the case of newspaper files or large microform sets. Librarians at UNC-CH found the center's policy of indefinite loan was especially useful to patrons; indeed, it may be a greater benefit than the holdings themselves. ${ }^{38}$ Such conditions of use are unique and cannot be replaced by regular interlibrary loan. Another unique service is the center's on-demand purchase policy, which applies to foreign dissertations as well as the purchase of already filmed newspapers and archival materials.

Although many of the items in CRL's collections are held elsewhere, the center is critical to scholars for access to materials held no place else. In addition, other libraries cannot match the center's conditions of loan. The uniqueness argument for belonging, therefore, is significant. Yet, because nonmembers can borrow up to ten items per year from the center for a fee of $\$ 12$ each, membership does not seem worthwhile if a library needs an occasional item that is held only by CRL. However, nonmembers cannot borrow unlimited amounts of materials nor can they keep them indefinitely.

\section{The Insurance Policy}

Implicit in some evaluations of membership in CRL is its value as an insurance policy. In times of tight funding, so the argument goes, members could rely on the center to supply certain specialized materials. Few libraries have approached the issue with actuarial precision, however. An insurance policy ought to be thoroughly investigated beforehand to make sure it meets needs. The effectiveness and value of the CRL insurance policy depend on two conditions: (1) relating probable local research needs to CRL's holdings; and (2) relating CRL and local collections so that they complement and supplement one another in meaningful ways.

Membership in the center is unlike most insurance policies in that there is no penalty for waiting to join until the need actually arises. Rather than pay the membership fee every year, a library might consider waiting to join until hard times arrive. Yet, without active participation from a large number of libraries, CRL would not be around when the need arises. In addition, if an institution does not participate on a continuing basis, it will have had no voice in determining the kinds of collections and services offered. Consequently, in times of financial austerity, membership might not be worth the cost because collections and services may not fit needs.

On the surface the insurance policy argument has a strong appeal. Its utility is undermined by the fact that many of CRL's holdings are available elsewhere. More fundamentally, do libraries ever collect any benefits from this policy? Documentation on withdrawal decisions indicates a basic difference between theory and practice. When financial difficulties arise, some libraries act as if CRL were a 
luxury rather than an insurance policy and withdraw..$^{39}$ Under such circumstances, two explanations are possible: libraries are forced to make a decision on the basis of short-term financial exigencies, or membership does not meet the two criteria of effectiveness mentioned above and, therefore, does not function as an effective insurance policy.

\section{Cost Avoidance}

Belonging to the center should allow libraries to save money that would otherwise be spent on exotic research materials. Cost avoidance is what a library does not have to buy, catalog, store, preserve-and possibly lend. At UNC-CH membership in CRL was used to avoid purchasing some materials identified in a major lacunae report that appeared shortly before the university joined. ${ }^{40}$ An institution can also realize immediate savings if it uses membership as an impetus to reevaluate its collection development programs. For example, prior to joining CRL, UNC-CH librarians felt it necessary to maintain a comprehensive collection of state documents. Shortly after becoming a member, UNC-CH decided to rely on the center's extensive holdings of state documents and greatly reduced its collecting scope, thereby saving money, space, and staff time. ${ }^{41}$ The savings that can be realized from cancellation of specialized serial titles held by the center are even more significant. One study comparing the overlap between current titles held by the University of Georgia and CRL estimated that the university library could save expenditures equal to the annual membership fee if it canceled only 20 percent of duplicate subscriptions. ${ }^{42}$

Membership also permits a library to tailor its acquisition of specific items to take advantage of the center's holdings. Microform holdings of foreign newspapers at $\mathrm{UNC}-\mathrm{CH}$, for example, are not as extensive as they might be, because of reliance on CRL for these materials. No new microform subscription to a newspaper is placed without reference to the center's holdings. In addition, UNC-CH generally does not purchase backfiles of newspapers if they are held at CRL. The same ap- plies to National Archives materials. Most of the expensive items purchased need to be approved by the Research Fund Committee, which is composed mainly of faculty. In order to maximize awareness of cooperative programs and increase the likelihood that UNC-CH acquisitions will complement rather than duplicate holdings available through resource-sharing arrangements, the application form for research funds asks if the material requested is held by local cooperative partners or CRL. Availability of an item from either source almost always results in rejection of the request.

Although UNC-CH librarians have never calculated the value of not having to acquire these materials, the savings are unquestionably in the thousands of dollars each year. Despite the fact that cost avoidance can be fairly easily demonstrated, the MGF report indicates that few members have estimated the value of acquisitions deferred because of the availability of material at the center. In fact, several collection development librarians stated that they rarely decided not to acquire an item because it was held by CRL ${ }^{43}$

Full members express their needs through the balloting process to determine what expensive items the center will acquire. Despite persistent urging, many institutions fail to vote. During the past fiscal year the mean number of members balloting was fifty-six, only slightly better than half. When a purchase proposal was exotic, participation dropped to a fifth. ${ }^{44}$ Finally, only 13 percent of members initiate recommendations for purchase. ${ }^{45}$ One can only speculate that perhaps members do not consider the cost avoidance argument or calculate its benefits because they often appear unconcerned about what the center acquires. ${ }^{46}$

At the same time cooperation exacts a price. Invariably a certain part of any institution's budget must be spent on salaries, buildings, and overhead. According to CRL, seventy-eight cents of every membership dollar goes to collections and direct services. ${ }^{47}$ Membership also results in added personnel costs at the local level. Every member must maintain records, 
thus incurring overhead costs. A few institutions also have a standing committee to monitor the relationship with CRL and encourage use. In some cases this represents significant staff time. Members who elect not to promote or monitor will find their relationship with the center tenuous; their collections will not be well integrated with CRL holdings; and they will have to be satisfied with less use.

Although active promotion increases the cost of membership by adding staff time, the effects of making local users aware of resources at CRL can be dramatic. UNC-CH librarians undertook major promotional campaigns consisting of mass distributions of CRL information, articles in the library newsletter, workshops on CRL and its collections, reference and interlibrary referrals, and mention in bibliographic instruction. These publicity efforts had a significant impact on usage. ${ }^{48}$

In addition, several members that have loaded the center's bibliographic records into the local online catalog have registered large increases in use. Ohio State, for example, reported a surge of 250 percent. ${ }^{49}$ Libraries paying thousands or even tens of thousands of dollars each year just to belong to CRL should consider promoting its use in this manner. So far, only five have done so. ${ }^{50}$

In conclusion, the cost avoidance rationale is both valid and compelling. Once again a major discrepancy exists between the theoretical and practical value of an argument in favor of membership. It is evident that members have generally failed to take full advantage of the center's holdings. We have not found any documentation indicating that CRL membership caused a library to review acquisitions programs-much less undertake a major retrenchment. Even in terms of specific items, librarians either ignore their membership in the center or fail to make users aware of its holdings.

\section{Some Deposit, Some Return}

Originally one of the most attractive features of CRL membership was its value as a cooperative storage warehouse. Indeed, during its early years deposits exceeded all other types of acquisitions. ${ }^{51}$ The cen- ter's potential for depositing uncommon materials appeals to librarians' deeply rooted sense of biblioecology: discard nothing of conceivable research value. The deposit function thus gives membership a strong psychological appeal as well.

Problems with cooperative storage have been principally due to a lack of space. After a lengthy moratorium, CRL is again accepting some materials for deposit. Few members have taken advantage of this option. The nature of low-use materials makes processing them extremely timeconsuming, while yielding little tangible return. ${ }^{52}$

The deposit function obviously appeals more to libraries that have space problems than to those that do not. It also puts the spirit of cooperation to the test. Without long-term commitment to the center, deposit-giving up research materials-is a risky affair, which dampens enthusiasm.

\section{"The deposit function is one theoret- ical argument in favor of member- ship that seems to have diminishing practical value."}

The center as a distant storage warehouse is no longer a major argument in favor of membership and is likely to be even less important in the future. The physical space issue may be eventually obviated by technology. If low-use materials can be economically stored on optical discs, why bother to send the paper to Chicago? The deposit function is one theoretical argument in favor of membership that seems to have diminishing practical value. It probably is the least appealing argument, for it involves some risk, yields little, and is labor intensive.

\section{Patron Perspectives}

Because CRL membership is sometimes vociferously debated by certain faculty, perceived needs merit special mention. The UNC-CH evaluation of CRL found that users were overwhelmingly positive about its services. Many graduate students, in particular, have benefited from 
the on-demand purchases. Even though this service is criticized as unsystematic collection development, it is one of the most valued features to many faculty and graduate students both at UNC-CH and other member institutions. ${ }^{53}$ Because of patron support for membership, a decision to withdraw would pose political problems for the library and require careful explanation.

Nevertheless, most users are not sufficiently knowledgeable to judge a reasonable cost for this service. User attitudes are different when the library does not absorb the costs, but instead passes them along. At UNC-CH, patrons were not willing to pay the transaction fees when CRL began to pass on charges for JAS photocopies. They typically preferred to obtain materials in the cheapest way possible, usually without regard to the length of time necessary.

Patron perspectives can also have negative consequences. The refusal of faculty to accept resource-sharing can work against full utilization of membership. One former member noted that active researchers were the leading opponents of resource-sharing programs, preferring to eliminate cooperative "services in order to maintain on-site resources in times of fiscal stringency." 54 Such opposition, in turn, can severely limit the benefits of CRL. In its study of membership, which resulted in withdrawal, the University of Waterloo concluded that "the existence of strong research collections at the Center has not deterred faculty members from requiring the purchase of the same collections by the Library." ${ }^{\prime \prime 5}$ Hence, we come back to the importance of accepting the obligation to cooperate and making it a local reality if the full benefits of CRL are to be realized.

\section{EVALUATION STRATEGIES}

Increasingly libraries are adopting the tools of scientific management to measure quantifiable benefits. Yet, "costing in complex organizations such as an academic library is a formidable task, and the literature indicates that it is discussed more than it is practiced." ${ }^{\prime \prime 6}$ Moreover, all evaluative methodologies are imperfect, and some situations defy rational evaluation because of an "excess of imponderables. ${ }^{\prime 57}$ Controversy permeates cost studies of service institutions. A lack of agreement in the discipline of decision making as to the precise distinctions between the various methods creates confusion, and the careless use of terms such as cost-effectiveness and cost-benefit analysis compounds the difficulties.

Nevertheless, the authors strongly concur with the recommendation of a recent report on the economics of research libraries sponsored by the Council on Library Resources that "investments in library operations and services need to be examined for cost, cost efficiency, and, where possible, cost benefits." 58 While such overarching goals as supporting scholarship and the life of the mind are intangible, they are no excuse for inefficiency, ineffectiveness, or lack of evaluation. ${ }^{99}$ As Peter Drucker shows, even the most sublime service institutions can have specific objectives that are real, verifiable, and measurable:

"Saving souls," as the definition of the objectives of a church, is, indeed, "intangible." At least the bookkeeping is not of this world. But church attendance is measurable. And so is "getting the young people back into the church."

Saving souls in library terms demands cooperation in the provision of specialized materials. While one cannot measure the ultimate value of meeting these needs, one can assess the specific contributions that the center can make to support scholarly salvation.

\section{The Cost of Assumptions and the Assumption of Costs}

Effective evaluation not only necessitates making objectives tangible and measurable, but it also demands that the questions be framed within the proper context. It must be emphasized that CRL is a means for acquiring, organizing, storing, preserving, and lending low-use materials. Cooperation on such an enterprise implies acceptance of certain values: commitment to the goals of scholarship and recognition of a class of materials needed by researchers that lies beyond an individ- 
ual library's ability to acquire, but which it nevertheless has an obligation to make available. Research of every type frequently requires access to specialized or low-use items. While providing this breadth of service is generally a costly endeavor, it is nevertheless at the heart of what research libraries assume to be their business.

\section{CRL as a Distant}

\section{"Special Collection"}

Because the center is a repository for specialized research materials, it invites comparison with special collection units on campus. Unlike these local units, membership in CRL does not excite donors and benefactors. Without special promotion it may remain an invisible asset and convey prestige only among a few researchers. On the other hand, both local special collections and the center can make significant contributions to scholarship if they are organically interrelated with curricular and research needs and promoted effectively.

\section{"Research libraries routinely assume certain high unit costs in supporting the academic endeavor, and any fis- cal analysis of the center must be framed within this context."}

Nevertheless, no matter how competently local or distant special collections are promoted, they will inevitably have high unit costs compared to general collections. Any fiscal analysis of special collections, therefore, must take this fact into account if holdings of specialized, low-use materials are to continue to exist in libraries. As Rebecca R. Martin states in a recent article, "By definition special collections serve a different purpose than do primary programs, and their justification and support cannot be based upon the principles used in austerity budgeting. ${ }^{\prime \prime 61}$ Research libraries routinely assume certain high unit costs in supporting the academic endeavor, and any fiscal analysis of the center must be framed within this context.

\section{Relative Value Analysis}

Library managers habitually review activities in terms of the cost per transaction. How much does it cost to process an interlibrary loan or acquire a book and make it available to users? Calculating the cost per transaction for CRL is relatively easy: Cost per transaction is the total annual membership fee and any special assessment divided by the number of requests filled.

The cost per transaction for using CRL is shocking. Based on the experience of UNC-CH and on documentation from other institutions made available to us, the typical cost per transaction is currently around \$200. Some libraries even report figures as high as $\$ 400 .^{62}$ Moreover, costs per transaction rose steeply with the imposition of surcharges for JAS because use declined dramatically. When the service was abandoned, cost per transaction rose even higher. One member reported an escalation from $\$ 19.13$ in $1981-82$ to $\$ 220.30$ in 1985-86-and then withdrew. ${ }^{63}$

Because this calculation looks at only one aspect of the benefits package, namely materials obtained, the center opposes it as reductionist. CRL's director contends that "transaction unit cost calculations employing use and other statistics (fill rate, request volume, etc.) and membership assessment and other costs for products and services ... rarely take into consideration all the tangible factors, not to mention the intangibles, involving CRL. The result tends to yield an unclear or unsatisfactory picture of CRL's true value to a member. ${ }^{1,64}$ Cost per transaction calculations measure one aspect of the center, namely, its utility as a document delivery source.

Although per transaction figures produce an initial emotional response, they may be entirely consonant with the cost of providing other research-oriented services. Within the context of special collections, the reported numbers are, in fact, quite reasonable. The Rare Books Curator at UNC-CH, for example, estimates that the average cost per volume purchased in 1986-87 was $\$ 190-$ and this figure ex- 
cludes selection, acquisitions, processing, and cataloging costs, which probably add at least another $\$ 50$ per volume to the cost. ${ }^{65}$ Even this total of $\$ 240$ represents only the cost of making one special collection item available for use. A per capita transaction cost based on the level of actual use received would be much higher.

A second means of relative value analysis asks, What does it cost to make the center's holdings available to all potential users? If one divides the membership costs by the total number of faculty and student potential users, the figure is minimal. At a major university such as UNC-CH the per capita cost for access to the center's vast holdings in 1986-87 was slightly more than one dollar. By way of comparison total campus library costs were $\$ 599$ per faculty member and student.

\section{Absolute Value Analysis}

It is possible to define and create a simple measure of benefit called "value received." With this approach one evaluates CRL in terms of its collections without regard to use. The key question is the scope and value of the holdings to which an institution gains access. Because CRL's holdings make it one of the largest research libraries in North America, membership significantly extends local holdings, even allowing for some duplication.

More than 3.5 million volumes reside in Chicago; there are 1.2 million microform units and about 16,000 current serial titles, including unparalleled collections of newspaper backfiles. Membership greatly extends the availability of scholarly resources at minimal cost. Using the mean membership fee, it costs less than half a cent each to gain access to all of the center's 4.5 million books and microforms. With the center's acquisitions budget for $1986-87$ of $\$ 617,180$, the mean membership fee buys thirty times as much material cooperatively as it would alone.

One can also assess the value of specific programs. Microforms are a good example because they are important to all members. If a library found, for example, that the dollar value of microforms for which it voted and which the center subsequently purchased exceeded the membership fee, then that library could probably be said to be receiving a good return on its investment. The few libraries that have made such calculations report benefits in the range of less than $\$ 1,000$ to more than $\$ 50,000$ annually. ${ }^{66}$ At UNC-CH the value received varies from $\$ 10,000$ to $\$ 30,000$ each year. Even those microforms that were not approved by a given library extend its collections, although perhaps in ways that are not evidently or immediately pertinent.

\section{Cost-Benefit Analysis}

Frequently recommended, but rarely applied to libraries, cost-benefit analysis poses fundamental questions about the value or worth of a particular course of action. Cost-benefit analysis takes into account all relevant factors and asks if the benefits justify the price. ${ }^{67}$ Consequently, this evaluation strategy demands that benefits be carefully defined and quantified.

Opinion varies considerably as to whether cost-benefit analysis is an appropriate tool for evaluating libraries. Some have argued, for example, against the application of cost-benefit analysis, because it requires that all factors be expressed in terms of dollars. They contend that not all benefits are susceptible to quantification. In this vein Paul Kantor has written that the benefits of information management reside ultimately in some impact on human minds or the "improvements in the decisions taken" as a result of the information made available. ${ }^{68}$ Others argue that even subjective values are quantifiable. To illustrate the difficulty, we can hardly begin to state what are the chief user benefits of CRL membership. Is it the vast resources or the indefinite loan period? Or is it what we can avoid buying?

The lack of a market price system makes it difficult to place a dollar figure even on those factors that can be quantified. ${ }^{69} \mathrm{Be}-$ cause of the difficulty in assigning dollar values, in practice much of what passes for cost-benefit analysis is actually costeffectiveness analysis. ${ }^{70}$ Yet, "where the objective is to minimize the cost of giving a service or producing a product, costbenefit analysis may not be necessary; comparing unit costs and cost effective- 
ness may be sufficient."

\section{Cost-Effectiveness Analysis}

Cost-effectiveness analysis "determines whether existing activities are being carried out efficiently. ${ }^{\prime 72}$ It is used to compare "different methods of providing the same library service. ${ }^{\prime 73}$ Cost-effectiveness analysis has also been defined as "costbenefit analysis without monetary valuation" of results. ${ }^{74}$ If a library could get CRL "products" in a different way, then it would have alternatives for providing the same service, and cost-effectiveness analysis would be appropriate. Because many former members have cited dispensability of the center's services as a reason for withdrawing, the question of costeffectiveness needs to be examined.

Hitch and McKean posit five major requirements for performing costeffectiveness analyses: defining objectives; specifying alternative means of achievement; ascertaining the cost of each option; creating models (using either mathematical equations or verbal statements) that relate costs to results; and devising a standard for rating the alternatives in order of desirability. ${ }^{75}$ Obviously, a careful execution of cost-effectiveness analysis requires skills of several types, from precise policy formulation to value assignment to hypothetical courses of action. It is institution-specific to a high degree.

If cost-effectiveness seems too formal and onerous, a shorter version of the comprehensive analysis could still provide useful management information. To determine whether CRL membership is the least-cost means of getting materials for patrons, one could examine the borrowing patterns over several years. Would it be possible to buy outright or borrow the items used by a member library in a given year? And what would it cost? It seems likely that in some years all requests filled by CRL could be purchased or obtained on ordinary interlibrary loan. In other years, it would not be possible to meet all patron requests through expenditures equal to the annual membership fee.

One must also consider the extra time, effort, and costs required to locate, ac- quire, process, and store items normally received through CRL. Undoubtedly a small class of items could not be obtained without Herculean efforts, considerable delays, and great inconvenience to the library and its users. One also needs to address the question of whether these items should be bought in the first place, since buying all requested materials would result in unbalanced collections and a shortsighted collection development program.

\section{CONCLUSION}

Evaluation of the center cannot ignore the fact that membership embodies a commitment to provide specialized material needed to support research. While CRL does express the values of research libraries, several means of realizing these goals through cooperative collection development are now available. Libraries must choose; the center must compete.

Some have argued that the center is a public good. Certainly it is in the public interest for such collections to exist; however, the center's mere existence is not sufficient grounds to command unqualified allegiance and support, for it is not the only means of cooperation to assure the availability of these items. Members and potential members must assess local needs to see if CRL or some other alternative best fulfills them.

As one ARL library director noted, CRL has attempted to be too many things to too many institutions, resulting in the concomitant tendency to let collection programs follow the possibilities of a given fee structure and membership base rather than the needs of the research library community. ${ }^{76}$ In light of the fluctuating nature of the center's programs, members need to monitor CRL and actively participate in its development.

This survey of the arguments for full CRL membership reveals that all are valid, although often benefits are heavily qualified by limitations of practice, the nature of the member library, or the cost of implementation. More fundamentally, the validity of the arguments is weakened when members fail to take full advantage of the center and do not promote it adequately. 
Members then compound this failure by not considering all of the arguments in favor of belonging and by erroneously evaluating benefits within the context of general library collections rather than special collections.

With regard to the various evaluation methodologies, cost-benefit analysis is not appropriate for assessing CRL membership, but cost-effectiveness analysis could be considered. Simpler measurements of benefits involving relative and absolute value analyses are also valid means of determining if membership is worth the cost. It is recommended that all three quantitative evaluations be employed at some level, for each provides a revealing perspective.

In conclusion, there can be no universally applicable methodology for evaluating membership in the Center for Research Libraries. Rather, each library must make an autonomous decision, because the tangible benefits of membership in CRL are highly situation dependent. For most general research libraries membership is a valid expression of cooperation and can be a justifiable means of gaining access to specialized materials.

\section{REFERENCES AND NOTES}

1. A search of the ERIC and LISA databases produced a mere dozen citations in which the center figures prominently, only one of which is based on research.

2. Information Systems Consultants Inc., "Options for the CRL: A Preliminary Report to the Membership, Governance, and Fees Committee: Final Report," (Bethesda, Md: ISC, Dec. 28, 1984), p.IV- 5 (hereafter referred to as the MGF report).

3. For background on UNC-CH's decision to join in 1976, see John Shipman, "Signifying Renewal As Well As Change: One Library's Experience with the Center for Research Libraries," Library Acquisitions 1:243-48 (1977). On our evaluation of membership (hereafter referred to as UNC-CH study), see University of North Carolina at Chapel Hill, Academic Affairs Library, CRL Subcommittee, "Report on CRL Membership" (Chapel Hill: UNC-CH, 1983).

4. Unless otherwise noted, all correspondence cited in this article comes from CRL member files and from materials distributed to board members. When permission to cite has been granted, then libraries are named. Otherwise, we try to be as specific as possible without identifying the institution. The same applies to studies of membership made available to us, most of which have been deposited with the center.

5. Information on the history and growth of CRL comes from its Annual Report; Ray Boylan, "The Center for Research Libraries," in Encyclopedia of Library and Information Science, ed. Allen Kent (New York: Dekker, 1983), V.36, p.156-67; Donald B. Simpson, "Center for Research Libraries: Meeting the Opportunity to Fulfill the Promise: A Symposium," Journal of Academic Librarianship 9:258-61 (1983); and Louis Kaplan, "The Midwest Inter-Library Center, 1949-1964," Journal of Library History 10:291-310 (1975).

6. The number of academic library consortia grew from less than a dozen in 1960 to 125 in 1970 and then mushroomed to 350 by 1975 . Ten years later the total was estimated to be in excess of 500 . Martin M. Cummings, The Economics of Research Libraries (Washington, D.C.: Council on Library Resources, 1986), p.47. For further analysis of these trends, see Joe A. Hewitt and John S. Shipman, "Cooperative Collection Development among Research Libraries in the Age of Networking: Report of a Survey of ARL Libraries," Advances in Library Automation and Networking 1:189-91, 202-3 (1987).

7. Kaplan, "The Midwest Inter-Library Center," p. 295.

8. MGF report, p.IV-10, IV-12. The question of cost is not insignificant for full members, who in the last fiscal year paid 96 percent of the total membership assessments as opposed to only 4 percent for associate and user members. The average assessment for full members in 1987 was $\$ 20,321$, with a range from $\$ 10,464$ to $\$ 36,562$. Center for Research Libraries, Board of Directors, Meeting 87-3, April 7, 1987, Confidential Fact Sheets for the Council Meeting, n.p.

9. This is the conclusion of a former chairman of the CRL board. Maurice Glicksman, "Some Thoughts on the Future of the Center for Research Libraries," Journal of Academic Librarianship 10:148 (1984). On the other hand, some full members rarely used JAS and objected to their assessments supporting this expensive service. Simpson, "Center for Research Libraries," p.259.

10. Boylan, "The Center for Research Libraries," p.156. This point is underscored by the fact that less 
than 4 percent of the items lent by CRL ever need to be recalled, and even these rare recalls involve only a few titles. p. 165 .

11. Glicksman, "Some Thoughts," p.149.

12. Hewitt and Shipman, "Cooperative Collection Development," p.197.

13. Ibid., p.201.

14. MGF report, p.IV-17. Research library directors are the most supportive of the center and most likely to consider it in a national context. Interlibrary loan librarians, who tend to see CRL in terms of document delivery, are the least supportive. Collection development officers fall in between. p.1-2. Such appears true of other cooperative ventures. The administration of Research Libraries Group institutions, for example, is very committed to its cooperative goals, but staff often lack understanding. Joseph J. Branin, "Issues in Cooperative Collection Development," in Issues in Cooperative Collection Development: Papers Presented at the SOLINET Resource Sharing and Networks Support Program, March 11, 1986 (Atlanta: Southeastern Library Network, n.d.), p.17.

15. Support for this is found in the MGF report, p.IV-2. Its survey revealed that members met $60-90$ percent of their interlibrary loans from just in-state institutions. In addition, their in-state fill rate was 70-95 percent, which was better than their estimated 50-75 percent fill rate with CRL.

16. For more information see Joe A. Hewitt, "Cooperative Collection Development Programs of the Triangle Research Libraries Network," Resource Sharing and Information Networks 2, no. 3/4:139-50 (Spring/Summer 1985); and Gary Byrd and others, "The Evolution of a Cooperative Online Network," Library Journal 110:71-77 (Feb. 1, 1985).

17. With the passage of each year RLG institutions account for an increasing proportion of Michigan's interlibrary loans, while CRL's share has declined. University of Michigan, Task Force on CRL, Revised Report (Ann Arbor:UM, Sept. 12, 1986) p.1 (hereafter referred to as Michigan study).

18. Susan K. Martin, letter to Donald Simpson, June 28, 1986.

19. This was the case at SUNY-Stony Brook. John Brewster Smith, letter to Donald Simpson, Jan. 27, 1986.

20. This was the experience of Wichita State University. See Jasper G. Schad, "View from a Former Member," Journal of Academic Librarianship 9:267-68 (1983).

21. For background on NCIP, see Nancy E. Gwinn and Paul H. Mosher, "Coordinating Collection Development: The RLG Conspectus," College \& Research Libraries 44:128-40 (1983); and Jutta Reed-Scott, Manual for the North American Inventory of Research Library Collections (Washington, D.C.: Assn. of Research Libraries, Office of Management Studies, Jan. 1985).

22. Joseph A. Rosenthal, "Toward a Viable Program for CRL-Back to Basics," Journal of Academic Librarianship 9:268 (1983).

23. Center for Research Libraries, Handbook (Chicago: CRL, 1987), p.1.

24. MGF report, p.IV-13.

25. Annual Report (1980-81), p.2.

26. Differences based on size can be seen in the fact that the larger libraries are most interested in microform sets, archival materials, and newspapers, while middle-size and small institutions are primarily interested in periodicals. MGF report, p.II-8.

27. MIT concluded that it had little use for the vast majority of CRL's collections and therefore could not justify membership. See Jay K. Lucker, "A Nonmember's Point of View, " Journal of Academic Librarianship 9:264-65 (1983). Because it has few programs in the humanities or area studies, the University of Western Ontario came to the same conclusion and subsequently withdrew. Robert Lee, letter to Donald Simpson, Sept. 9, 1985. This was also the reason behind Oklahoma State University's withdrawal. Roscoe Rouse, letter to Roger K. Hanson, Dec. 17, 1986. For a similar point of view from Drexel, then an associate member, see Richard L. Snyder, "A Technological University's View," Journal of Academic Librarianship 9:263-64 (1983). In addition, CRL's collections do not necessarily correspond to the research interests even at a general university. This was the case at SUNY-Stony Brook and was a major factor in its decision to withdraw. John Brewster Smith, letter to Donald Simpson, Jan. 27, 1986.

28. The center's director acknowledged the conflicts posed by diversity when he wrote that a central governance and financial question was whether membership should be reduced to a smaller and more homogeneous group. Simpson, "Center for Research Libraries," p.260. This was also one of the recommended options of the MGF report, p.V-4, VI-8-VI-13.

29. On the inability of even a small, homogeneous group of Midwest research libraries to achieve consensus on this issue, see Elaine Sloan, "A View from an Original Member," Journal of Academic Librarianship 9:263 (1983).

30. This was also the consensus of a survey of a dozen directors of nonmember libraries surveyed. They viewed the center as "a specialized organization for academic research libraries with collec- 
tions and services generally not relevant to their needs." None of them considered membership to be a good investment, and only two would use the CRL even if fees were levied solely on the basis of use. MGF report, p.IV-9.

31. This was a basic conclusion of the MGF report, p.IV-17.

32. Ibid., p.IV-11.

33. Sarah E. Thomas, "Collection Development at the Center for Research Libraries," College \& Research Libraries 46:233 (1985). The level of uniqueness varied according to language, with a range from 71 percent in the case of Urdu to 6 percent for German. Since this article appeared, CRL has canceled approximately 1,100 subscriptions to titles widely held by members. The level of uniqueness has probably increased.

34. MGF report, p.IV-10.

35. UNC-CH study, p.17.

36. Schad, "View from a Former Member," p.268.

37. Eighty-two percent of the respondents to a survey indicated that their research would have been adversely affected without material from the center. UNC-CH study, p.15.

38. UNC-CH study, p.4, 17. Fifty-one percent of the respondents to a survey indicated that the indefinite loan period was useful, p.15.

39. According to a former chairman of the CRL board, reduced funding was a major impetus behind withdrawals. Glicksman "Some Thoughts," p.149. See also Schad, "View from a Former Member," p.268. Moreover, one large research library in the Midwest acknowledged that it was forced to end membership because of "immediate and pressing financial problems," even though satisfied with the center and its programs.

40. UNC-CH study, p.4.

41. UNC-CH study, p.6-7.

42. Thomas, "Collection Developments," p.234.

43. MGF report, p.IV-5. The authors of the Michigan study note that the university library had "not been considering CRL's purchasing decisions as a factor in our decision-making for some time." In part this situation results from the excessive amount of time it takes the center to decide on a subscription or major microform purchase. By the time CRL finally makes a decision, the other library may already hold the relevant materials. Michigan study, p.4. Such is also the experience of the University of California nine-campus system. Marion L. Buzzard, "Cooperative Acquisitions within a System: The University of California Shared Purchase Program," Resource Sharing and Information Networks 2, no.3/4:102 (Spring/Summer 1985).

44. Center for Research Libraries, "Report on Purchase Proposals: FY 1987 Purchase Proposals: Summary Report," Feb. 3, 1987.

45. Donald B. Simpson, letter to John Rutledge and Luke Swindler, Nov. 25, 1987.

46. Support for this statement is provided by the survey of collection development officers conducted on behalf of the center. Only two-fifths considered it very important to influence the scope and contents of CRL's collections. MGF report, p.IV-6.

47. Donald B. Simpson, letter to John Rutledge and Luke Swindler, Nov. 25, 1987. In 1985 the figure was seventy-two cents. Center for Research Libraries, Board of Directors, Meeting 86-1, Oct. 10, 1985 , n.p.

48. UNC-CH study, p.9-10, 13.

49. Center for Research Libraries, Board of Directors, Meeting 87-3, Apr. 6, 1987, p.3.

50. According to CRL, the annual cost of acquiring its bibliographic tapes is estimated to be $\$ 150$. Donald B. Simpson, letter to John Rutledge and Luke Swindler, Nov. 25, 1987. Solid data on the additional costs of downloading, cleaning up, and storing external MARC tapes are nonexistent.

51. Kaplan, "The Midwest Inter-Library Center," p.297.

52. A good example of this is provided by an early attempt to encourage members to deposit broken serial runs with the center so as to create complete backfiles. The results were disappointing because of the time that would have been required to check the titles needed by CRL against local holdings and then change serials records. Ibid., p. 298.

53. On the widespread support for this program see Center for Research Libraries, Summary of CRL Regional Meetings, Apr. 7-May 15, 1984, June 18, 1984.

54. Schad, "View from a Former Member," p.267.

55. Bruce MacNeil and Stuart MacKinnon, memorandum to Senate Library Committee, Nov. 27, 1986, p.4. Negative patron perspectives may be greatest at small institutions. In explaining its decision to withdraw, Wichita State noted active scholars are the most opposed to cooperative programs: "Acutely aware of the limited collections available to them, academic researchers favor citing services [such as CRL] in order to maintain on-site resources in times of fiscal stringency." 
Schad, "View from a Former Member," p.267.

56. Colin K. Mick, "Cost Analysis of Information Systems and Services," Annual Review of Information Science and Technology 14:44 (1979).

57. Mark S. Thompson, Benefit-Cost Analysis for Program Evaluation (Beverly Hills, Calif.: Sage, 1980), p.223.

58. Cummings, The Economics, p.76.

59. F. W. Lancaster, The Measurement and Evaluation of Library Services (Washington, D.C.: Information Resources Pr., 1977), p.5.

60. Cited in Lancaster, "The Measurement," p.5.

61. Rebecca R. Martin, "Special Collections: Strategies for Support in an Era of Limited Resources," College \& Research Libraries 48:241 (1987).

62. MGF report, p.IV-10.

63. MacNeil and MacKinnon, memorandum, p.2. The figures are in Canadian dollars.

64. Donald B. Simpson, "Director's Statement on the CRL Collection Management/Cost Avoidance Model," May 15, 1985, n.p.

65. In 1984, a study of university libraries found that the average cost of selecting, acquiring, and originally cataloging a monograph was $\$ 27.36$. Cummings, The Economics, p.104. Taking into account inflation and the higher cost of acquiring and processing special collections materials, $\$ 50$ per title would seem to represent a minimal estimate.

66. MGF report, p.IV-5.

67. Lancaster, The Measurement, p.1.

68. "Cost and Productivity in Library Operations," in Productivity in the Information Age (Proceedings of the 46th ASIS Annual Meeting), V.20, ed. Raymond F. Vondran and others (Washington D.C.; ASIS, 1983), p.297.

69. Cummings, The Economics, p.77.

70. Lancaster, The Measurement, p.2; and Nancy van House, "Research on the Economics of Libraries," Library Trends 32, no. 4:414 (Spring 1984).

71. Cummings, The Economics, p.77.

72. Murray Martin, "Cost-Benefit Analysis for Austerity," in Austerity Management in Academic Libraries, ed. John F. Harvey and Peter Spyers-Duran (Metuchen, N.J.: Scarecrow, 1984), p.237. A related and generally inseparable measure is cost-performance-benefit analysis, which "relates the entire spectrum of costs, performance (level of effectiveness), and benefits." Lancaster, The Measurement, p.322.

73. van House, "Research," p.414.

74. Thompson, "Benefit-Cost Analysis," p.225.

75. Cited in Lancaster, The Measurement, p.325-27.

76. Rosenthal, "Toward a Viable Program," p.269. 